\title{
PKM Pengelolaan Bisnis Berbasis Entrepreneurship pada Pengrajin Keset Kaki Desa Panggungduwet
}

\author{
Sri Nathasya Br Sitepu \\ Departemen International Business Management, Fakultas Manajemen dan Bisnis, Universitas Ciputra Surabaya \\ CitraLand CBD Boulevard, Made, Surabaya, 60219, Jawa Timur, Indonesia
}

\author{
ARTICLE INFO: \\ Received: 2020-04-10 \\ Revised: 2020-05-20 \\ Accepted: 2020-06-02
}

Keywords:

Business; Craftsmen; Entrepreneurship

\begin{abstract}
Entrepreneurship-based business management for doormats craftsmen in Panggungduwet Village. The number of craftsmen who participated in the PKM program was 10 people. PKM collaborates with the Panggungduwet Village government and the Faculty of Management, Ciputra University. Craftsmen problems: (1) Doormats business without innovation; (2) The conventional sales system; (3) The doormat business generates low income (less than 1 million/month); (4) Doormats craftsmen without entrepreneurship-based business management knowledge; (5) Doormats craftsmen are afraid to sell products through an online sales system; (6) The character of the craftsmen did not believe in himself. PKM goals: improve the quality of human resources from craftsmen, business management and reduce the number of poor people in Panggungduwet Village. The PKM activity methods consist of: Business Model Canvas analysis, business management innovation, and business evaluation. PKM Results: (1) Innovation of the entrepreneurship-based doormat business management system by developing customer relationships; (2) Marketing media innovation with social media; (3) Creating jobs for 20 people in Panggungduwet Village who become doormats craftsmen; (4) Increasing 15\% income craftsmen; (5) Increase the understanding of craftsmen on the concept of entrepreneurship; (6) Increased self-confidence of craftsmen in running business operations and executing product sales with an online system.
\end{abstract}

(C) 2020 Published by University of Merdeka Malang. This is an open access article distributed under the CC BY-SA 4.0 license (https://creativecommons.org/licenses/by-sa/4.0/)

How to cite: Sitepu, S. N. B. (2020). PKM Pengelolaan Bisnis Berbasis Entrepreneurship pada Pengrajin Keset Kaki Desa Panggungduwet. Abdimas: Jurnal Pengabdian Masyarakat Universitas Merdeka Malang, 5(3), 239-248. https://doi.org/10.26905/abdimas.v5i3.4201

\section{PENDAHULUAN}

Desa Panggungduwet berada di Kecamatan Kademangan Kabupaten Malang Provinsi Jawa Timur. Desa Panggungduwet berada didaerah pesisir pantai dengan jarak temupuh 192 km dari pusat Kota Surabaya. Lokasi Desa Panggungduwet berada di daerah perbukitan sehingga sulit mendapatan air bersih. Masyarakat hanya mengandalkan air tadah hujan dan sumur bor untuk memenuhi kebutuhan air namun,

Corresponding author: Sri Nathasya Br Sitepu: Tel. +62 317451699 | E-mail: nathasya.sitepu@ciputra.ac.id 
ABDIMAS: Jurnal Pengabdian Masyarakat Universitas Merdeka Malang Volume 5, No 3, November 2020: 239-248

kondisi lingkungan desa tetap bersih. Akses jalan raya sudah tersambung jalan aspal hingga Kabupaten Blitar.
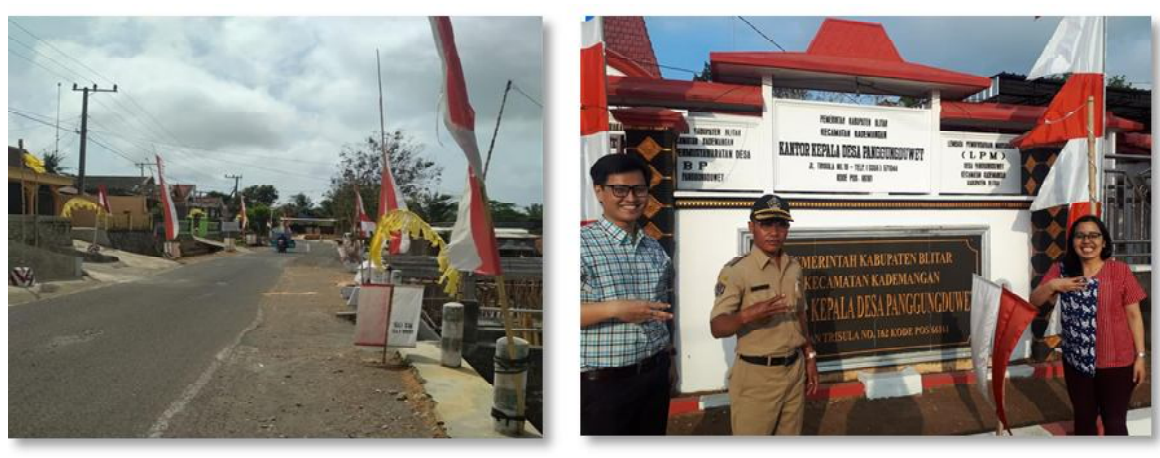

Gambar 1. Lokasi Desa Panggungduwet

Gambar 2. Koordinasi dengan Kepala Desa Panggungduwet

Berdasarkan data administrasi desa tahun 2018 terdapat 1.327 kepala keluarga dengan jumlah total penduduk 3.870 jiwa dengan rincian 1.953 penduduk laki-laki dan 1.917 penduduk wanita.

Penduduk Desa Panggungduwet memiliki pendapatan rata-rata sebesar Rp.750.000/bulan. Jumlah pendapataan yang relatif kecil membuat kondisi penduduk berada digaris kemiskinan. Penduduk Desa Panggungduwet teridentifikasi bekerja dalam beberapa sektor yaitu: sektor pertanian, jasa/perdagangan, industri dan sektor lain-lain. Berdasarkan data perekonomian desa, penduduk yang bekerja disektor pertanian berjumlah 1428 orang, bekerja disektor jasa berjumlah 842 orang, yang bekerja di sektor industri 167 orang, dan bekerja disektor lain-lain 384 orang. Kesimpulan dari data ekonomi jumlah penduduk yang mempunyai mata pencaharian berjumlah 2821 orang.

Penduduk yang mayoritas bekerja di sektor pertanian belum maksimal menghasilkan produk pertanian sehingga harga jual produk pertanian rendah dan dampak akhirnya banyak penduduk desa yang miskin. Pemberdayaan masyarakat yang berprofesi sebagai petani secara intensif maka akan mampu mengangkat harkat dan martabat masyarakat untuk melakukan berusaha (Mangowal, 2013). Kemiskinan adalah masalah Desa Panggungduwet. Solusi kemiskinan yang diambil pemerintahan Desa bekerjasama dengan Fakultas Manajemen Universitas Ciputra membuat PKM pengelolaan bisnis berbasis entrepreneurship bagi pengarajin keset kaki Desa Panggungduwet. Pemerintah Desa Panggungduwet berkolaborasi dengan dosen-dosen Fakultas Manajemen Universitas Ciputra dan pengrajin keset kaki. PKM ini dilakukan selama satu bulan pada tahun 2019. Dokumentasi kunjungan pertama dosen Fakultas Manajemen Universitas Ciputra untuk menggali permasalahan yang dihadapi Desa Panggungduwet.

Bisnis keset kaki merupakan sumber alternatif tambahan pendapatan bagi penduduk Desa Panggungduwet. Tambahan pendapatan ini diperlukan untuk memenuhi kebutuhan rumah tangga. Pendapatan dari bisnis keset kaki digunakan ibu rumah tangga untuk memenuhi kebutuhan keluarga yang tidak tercukupi dari penghasilan utama yang berasal dari sektor pertanian. Pengrajin keset kaki Desa Panggungduwet menjalankan usaha dengan cara berkelompok. 


\section{PKM Pengelolaan Bisnis Berbasis Entrepreneurship pada Pengrajin Keset Kaki Desa Panggungduwet}

Sri Nathasya Br Sitepu

Pengrajin keset kaki sudah mulai menjalankan bisnis sejak tahun 2010. Bahan baku berupa kain perca diperoleh dari Kota Malang dan Kota Surabaya. Bisnis kerajinan keset kaki dikerjakan secara berkelompok oleh ibu rumah tangga. Desa Panggungduwet memiliki 10 kelompok pengrajin keset kaki. Kelompok terdiri dari 3 orang hingga 10 orang. Ibu rumah tangga yang mengerjakan kerajinan keset kaki tidak lulus sekolah dasar atau maksimal hanya lulus SD. Berikut ini adalah kondisi bisnis keset kaki di Desa Panggungduwet: (1) Proses pembuatan keset kaki menggunakan alat sangat sederhana (cetakan keset kaki dari besi dan kayu); (2) Bisnis keset kaki tidak memiliki inovasi (tanpa konsep model bisnis berbasis entrepreneurship); (3) Sistem penjualan konfensional (tidak memanfaatkan teknologi) hanya mengandalkan pembeli dari Kota Blitar dan Surabaya untuk membeli produk kerajinan yang dihasilkan; (4) Bisnis keset kaki menghasikan pendapatan yang rendah berkisar antara Rp.300.000- Rp.1.000.000/bulan; (5) Lokasi bisnis kerajinan keset kaki jauh dari Kota Blitar dan Surabaya menyebabkan biaya pemasaran jika ke kota menjadi tinggi; (6) Pengrajin keset kaki dikerjakan pada saat waktu luang dari ibu rumah tangga; (7) Pengrajin keset kaki tidak memiliki pengetahuan tentang pengelolaan bisnis berbasis entrepreneurship; (8) Pengrajin keset kaki takut menjual produk melalui sistem penjualan online; (9) Karakter pengrajin tidak pecaya terhadap kemampuan diri sendiri.

Kondisi ini diatas dapat disimpulan menjadi kondisi operasional bisnis (poin 1-5) dan kondisi pengelola bisnis (pengrajin) bisa dilihat dari poin 6-9. Hal diatas menyebabkan bisnis keset kaki berjalan stagnan tanpa peningkatan bisnis.

Tujuan pertama program PKM pengelolaan bisnis berbasis entrepreneurship pada pengrajin keset kaki Desa Panggungduwet untuk meningkatkan pemahaman pengrajin keset kaki pada konsep entrepreneurship. Tujuan PKM yang kedua untuk inovasi pengelolaan bisnis berbasis entrepreneurship. Tujuan PKM ketiga untuk membantu pemerintah Desa Panggungduwet menyelesaikan masalah ekonomi melalui meningkatkan pendapatan penduduk sehingga terjadi penurunan jumlah penduduk miskin di Desa Panggungduwet.

\section{METODE}

Program PKM pengelolaan bisnis berbasis entrepreneurship pada pengrajin keset kaki Desa Panggungduwet dilakukan dalam bentuk pelatihan dengan tiga metode pendekatan yaitu, observasi, eksekusi pengelolaan bisnis, dan evaluasi. Pelaksanaan setiap tahapannya melibatkan kolaborasi dari pemerintah desa dalam hal ini di damping oleh Pak Winarno (kepala desa), Dosen Fakultas Manajemen dan Bisnis diwakili oleh Ibu Sri Nathasya dan Pak William serta seluruh pengrajin keset kaki di Desa Panggungduwet dan aktif menjalanankan bisnis. Gambar 3 merupakan metode dari kegiatan PKM.

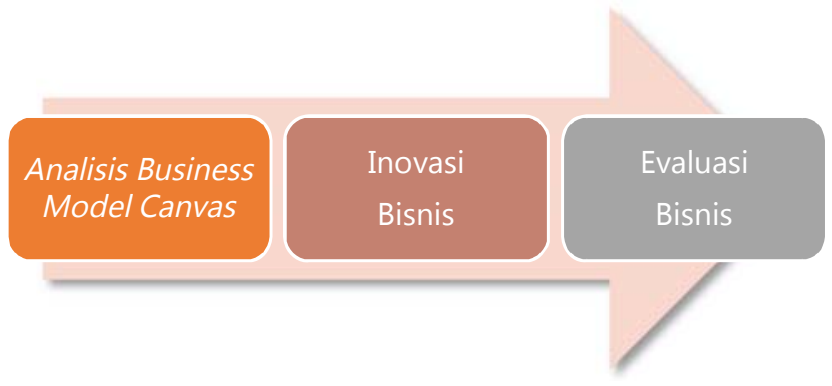

Gambar 3. Metode kegiatan PKM 
ABDIMAS: Jurnal Pengabdian Masyarakat Universitas Merdeka Malang

Volume 5, No 3, November 2020: 239-248

Metode kegiatan memiliki hubungan antara satu metode dengan metode lainnya. Pengrajin keset kaki Desa Panggungdwet mengikuti dan sangat kooperatif pada setiap tahapannya. Lokasi pelaksanaan kegiatan dari setiap metode berlangsung dirumah pengrajin yang sekaligus berfungsi sebagai tempat produksi kerajinan keset kaki. Pelatihan entrepreneurship nantinya diharapkan mampu mendorong semangat berwirausaha dan motivasi peserta untuk menjalankan usaha dengan baik dan optimal (Susita et al., 2017). Tolak ukur keberhasilan dari pelatihan berupa kemampuan pengrajin keset kaki melakukan inovasi model, penggunaan alat bantu (tidak fokus mengandalakan kekuatan pengrajin), kemampuan dalam pembuatan laporan keuangan dan manajemen usaha (Harahap \& Amanah, 2018).

\section{Business Model Canvas (BMC)}

Business Model Canvas (BMC) merupakan suatu metode analisis model bisnis terdiri dari 9 bagian yang dibuat secara visual sehingga mudah untuk dimengerti dan dipahami. Komponen dari Business Model Canvas (BMC) diantaranya: key activities, key patners, value proportion, customer relationship, key resources, cost, channels, Revenue, dan customer segmen. BMC mampu menjelaskan, visualisasi, menilai, dan mengubah suatu model bisnis, sehingga menghasilkan kinerja yang maksimal (Osterwalder \& Pigneur, 2010). Gambar 4 adalah visual dari 9 blok BMC yang penting dianalisis dalam sebuah bisnis.

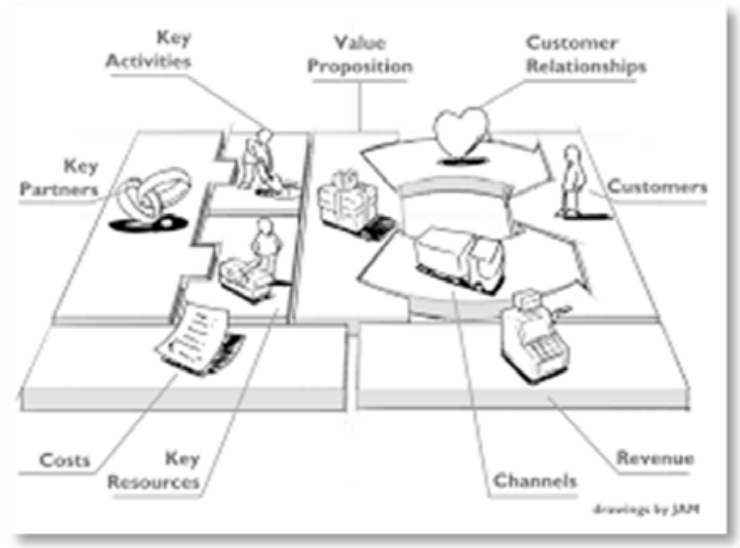

Gambar 4. Block Business Model Canvas

Metode PKM pertama yang dijalankan berupa analisis Business Model Canvas (BMC) dari setiap kelompok pengrajin. Pada tahapan ini dosen dan kepala Desa Panggungduwet membantu dosen untuk menunjukkan lokasi rumah pengrajin. Setelah bertemu dengan pengrajin pada tahap awal dosen memberikan pemahaman terkait bisnis dan peran BMC dalam mengoptimalkan bisnis keset kaki.

\section{Inovasi Bisnis}

Inovasi merupakan ide yang berhubungan dengan barang, jasa yang dianggap baru dimana, realisasi dari ide dapat dilihat dan dirasakan oleh seseorang (Hadiyati, 2011). Inovasi berpengaruh terhadap keunggulan bersaing dari unit bisnis baik sekala kecil hingga unit bisnis sekala besar (Lestari et al., 2019). Pengrajin yang sudah menyusun Business Model Canvas (BMC) bisnis keset kaki selanjutnya berinovasi. 


\section{PKM Pengelolaan Bisnis Berbasis Entrepreneurship pada Pengrajin Keset Kaki Desa Panggungduwet}

Sri Nathasya Br Sitepu

Inovasi atau perubahan pada pengelolaan bisnis dilakukan oleh pengrajin keset kaki. Inovasi bisnis merupakan praktek pembelajaran entrepreneurship. Konsep entrepreneurship merupakan disiplin ilmu yang membahas dan mempelajari nilai (value), kapasitas (ability) dan sikap seseorang ketika menghadapi tantangan hidup untuk mendapat peluang dengan berbagai risiko yang mungkin dihadapinya (Subroto, 2015). Pendidikan entrepreneurship yang dibeikan kepada pengrajin keset kaki bertujuan agar pengrajin keset kaki menjadi entrepreneur. Entrepreneur sukses selalu kreatif dan menggunakan kreativitasnya tersebut untuk menghasilkan profit bisnis.

Hisrich et al. (2005) menjelaskan beberapa nilai (value) umum digunakan sebagai karakteristik keberhasilan entrepreneurship, yaitu: (1) Rencana menghasilkan produk superior; (2) Kualitas pelayanan yang diberikan kepada konsumen; (3) Fleksibel; (4) Kompetensi dari manajemen; (5) Karakter sopan santun dan etika; (6) Usaha entrepreneur dalam menciptakan peluang bisnis dengan cara membangkitkan keberanian dan kebebasan dalam menciptakan barang dan jasa. Entrepreneurship merupakan kapasitas pengusaha agar lebih kreatif dan memanfaatkan inovasi pada setiap kegiatan bisnisnya sehari-hari. Pengrajin keset kaki diharapkan mampu melakukan inovasi bisnis keset kaki. Inovasi yang diharapkan dari pengrajin adalah kemampuan untuk melakukan, menciptakan suatu hal yang berbeda dari yang sudah ada sebelumnya.

Inovasi dari pengrajin dengan cara melihat hasil BMC dan mengkombinasikan dengan pemahaman terkait entrepreneurship. Eksekusi inovasi pada awal memberikan kesempatan kepada pengrajin untuk melakukan tray dan error. Kelompok pengrajin saling berdiskusi untuk memilih ide inovasi yang akan dieksekusi. Potensi lingkungan dan sumber daya juga menjadi pertimbangan dalam berinovasi.

\section{Evaluasi}

Evaluasi merupakan tahapan penting pada pembelajaran pengeloaan bisnis berbasis entrepreneurship. Evaluasi melihat dan mengukur pengaruh inovasi pada kesuksesan bisnis kerajinan keset kaki. Dosen pendamping program PKM mengunjungi kelompok pengrajin dengan membawa BMC yang lama serta membandingkan dengan BMC yang sudah menjalankan inovasi. Proses evalusi berjalan dengan dialog interaktif antara dosen pendamping PKM dengan pengrajin. Kepala Desa Panggungduwet juga hadir dan mendampingi proses evaluasi bisnis. Proses evaluasi berlangsung sekitar 1 jam pada setiap kelompok pengrajin.

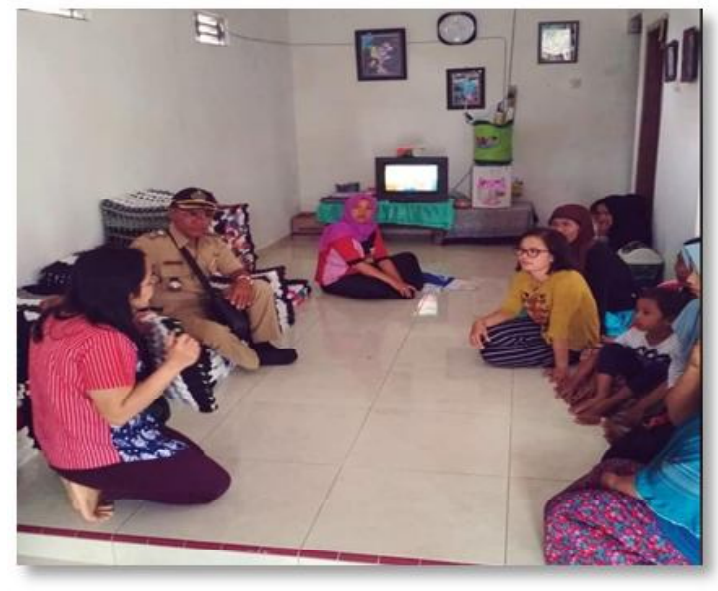

Gambar 5. Evaluasi pengelolaan bisnis keset kaki 
ABDIMAS: Jurnal Pengabdian Masyarakat Universitas Merdeka Malang Volume 5, No 3, November 2020: 239-248

Kegiatan evaluasi bisnis keset kaki juga mengukur dampak positif dari inovasi terhadap kemajuan bisnis. Selain dampak positif proses evaluasi juga memetakan kendala dalam inovasi BMC. Pengrajin berhasil menemukan inovasi bisnis saat evaluasi. Inovasi bisnis ditemukan lebih aplikatif karena mendapatkan masukan berdasarkan contoh dari bisnis pengrajin keset kaki di kota lain. Pengrajin mendapat masukan dari dosen berupa pengalaman dan teori entrepreneurship.

\section{HASIL DAN PEMBAHASAN}

Keberhasilan program PKM pengelolaan bisnis berbasis entrepreneurship bagi pengarajin keset kaki Desa Panggungduwet dapat dilihat dari 3 pencapaian. Hasil PKM dapat dirasakan oleh pengrajin secara individu (peningkatan soft skill). Harini (2014) pelatihan entrepreneurship mempunyai pengaruh positif terhadap pelaku usaha (entrepreneur) skala mikro. Perubahan juga terjadi pada kinerja (pengelolaan) bisnis sekaligus berdampak positif bagi pemerintah Desa Panggungduwet.

\section{Peningkatkan pemahaman pengrajin keset kaki pada konsep entrepreneurship}

Pengrajin keset kaki Desa Panggungduwet setelah mengikuti program PKM telah memahami konsep entrepreneurship. Pengrajin mengerti dan mampu menganalisis dengan Business Model Canvas (BMC). Hasil penyusunan BMC bisnis keset kaki pengrajin melihat kekurangan dari pengelolaan bisnis. Kelemahan dalam pengelolaan bisnis pada bagian customer relationship yang sama sekali belum dimiliki pengrajin. Pengrajin mengawali dengan cara mengidentifikasi key patners merupakan orang yang membantu yaitu, mitra penjual kain perca yang berlokasi di Kota Surabaya dan Kota Malang. Mitra penjual kain perca berasal dari industri tekstil yang memiliki limbah potongan kain yang tidak terpakai. Penjual alat cetak keset kaki juga merupakan mitra penting karena menyediakan alat cetak keset kaki yang terbuat dari besi dan kayu. Pengrajin juga memiliki pemerintah desa yang menjadi key patners dimana pemerintah desa banyak membantu pengrajin dalam mengembangkan bisnis. Salah satu support pemerintah desa adalah kolaborasi dengan Fakultas Manajemen Bisnis Universitas Ciputra untuk membantu pengrajin agar dapat mengelola bisnis berbasis entrepreneurship.

Key activities adalah kegiatan penting dalam bisnis. Kegiatan yang dilakukan pengrajin adalah mengayam kain perca menghasilkan keset kaki. Sebuah keset kaki membutuhkan waktu pengerjaan selama 10 menit jika kain perca telah dipilah. Key resources dari bisnis menggunakan alat cetak sederhana berbahan besi dan kayu untuk mengayam kain perca. Gunting juga merupakan alat untuk membuat keset kaki. Gambar 6 adalah dokumentasi dari alat cetak yang digunakan pengrajin.
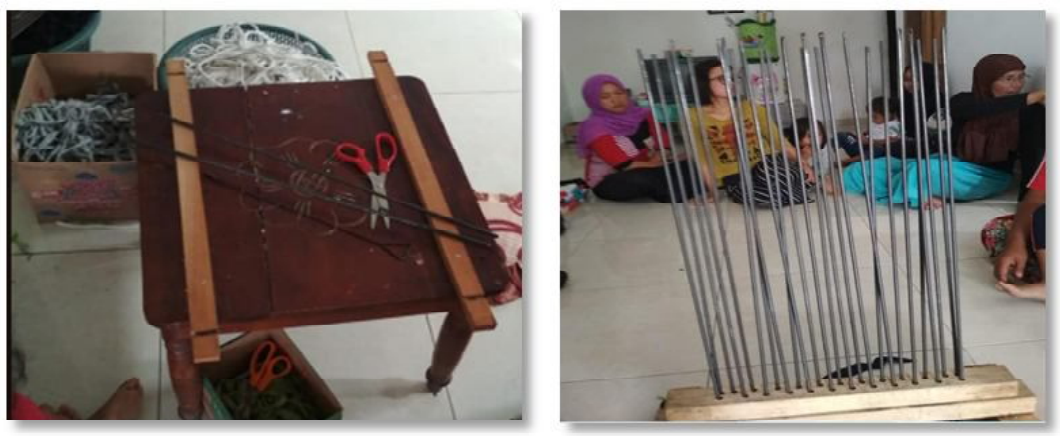

Gambar 6. Alat cetak keset kaki

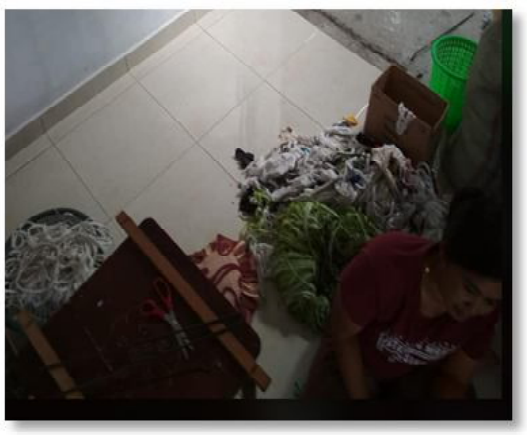

Gambar 7. Kain perca bahan baku keset kaki 


\section{PKM Pengelolaan Bisnis Berbasis Entrepreneurship pada Pengrajin Keset Kaki Desa Panggungduwet}

Sri Nathasya Br Sitepu

Selain alat cetak bahan terpenting untuk menghasilkan keset kaki adalah kain perca (Gambar 7). Kain perca yang merupakan kain limbah dari pabrik tekstil yang dibeli pengrajin dan dikemas oleh mitra dalam karung yang besar. Pengrajin akan memilih kain perca berdasarkan warna yang sama sehingga pada saat proses pengayaman lebih singkat untuk menghasilkan keset kaki dengan warna yang sama. Kain perca terdiri bermacam-macam warna dan ukuran sehingga pengrajin perlu memilah terlebih dahulu.

Value proportion dari bisnis kain perca ini sangat luar biasa. Bisnis kain perca yang digeluti oleh pengrajin Desa Panggungduwet mampu mengolah limbah tekstil (kain perca), mengurangi sampah serta menambah nilai ekonomi yang lebih tinggi. Value proportion kedua dapat menciptakan lapangan kerja bagi ibu rumah tangga di Desa Panggungduwet. Aktivitas yang dilakukan pengrajin sudah sesuai dengan tujuan dari entrepreneurship. Dollinger (2008) menjelaskan entrepreneurship adalah proses atau kegiatan kreatif dan inovasi untuk menghasilkan perubahan melalui pemanfaatan peluang dan sumber-sumber yang tersedia agar menghasilkan nilai tambah terhadap diri sendiri, orang lain, lingkungan, dan keberhasilan memenangkan persaingan.

Customer relationship berhubungan dengan cara pengrajin untuk membuat agar pelanggan tetap menyukai keset kaki yang diproduksi. Pengrajin keset kaki belum melakukan upaya apapun terkait customer relationship. Pengrajin memiliki channel terbatas untuk memasarkan keset kaki. Pengrajin hanya mengandalkan mitra penjual kain perca untuk membeli produk dengan sistem borongan. Sistem penjualan keset kaki terbatas pada mitra yang membeli seluruh keset kaki. Pengrajin wajib menjual seluruh produk keset kaki dari kain perca yang sudah dijual oleh mitra. Sistem penjualan ini semacam sistem tengkulak yang sangat mengikat pengrajin. Customer segmen untuk bisnis keset kaki ini cukup besar. Customer segmen atau orang yang berpeluang membeli produk ini terdiri dari, ibu rumah tangga, pengelola rumah sakit, pengelola perkantoran, dan pengelola guest house. Pertumbuhan kinerja usaha kecil menengah ditentukan oleh strategi komunikasi pemasaran dan komitmen organisasional dari pelaku bisnis (Suryana et al., 2019).

BMC yang membahas terkait keuangan yaitu cost structure dan revenue stream. Cost structure merupakan biaya yang dikeluarkan pengrajin adalah biaya pembelian kain perca. Revenue stream menganalisis sumber pendapatan dari bisnis. Revenue stream bisnis bersumber dari hasil penjualan keset kaki kepada mitra penjual kain perca. Secara keseluruhan Business Model Canvas (BMC) yang disusun pengrajin seperti pada Tabel 1.

Tabel 1. BMC bisnis kerajinan keset kaki Desa Panggungduwet

\begin{tabular}{|c|c|c|c|c|c|}
\hline & Mitra Utama & Kegiatan Utama & Proporsi Nilai & $\begin{array}{c}\text { Hubungan Dengan } \\
\text { Pelanggan }\end{array}$ & $\begin{array}{c}\text { Segmentasi } \\
\text { Pelanggan }\end{array}$ \\
\hline \multirow{2}{*}{$\begin{array}{l}1 . \\
2 .\end{array}$} & $\begin{array}{l}\text { Penghasil kain } \\
\text { perca }\end{array}$ & $\begin{array}{l}\text { Menganyam kain } \\
\text { perca }\end{array}$ & \multirow{3}{*}{$\begin{array}{l}\text { 1. Mengolah } \\
\text { sampah (kain } \\
\text { perca) } \\
\text { 2. Membuka } \\
\text { lapangan kerja } \\
\text { bagi ibu rumah } \\
\text { tangga }\end{array}$} & Tidak ada & $\begin{array}{l}\text { 1. Ibu rumah } \\
\text { tangga }\end{array}$ \\
\hline & \multirow{2}{*}{$\begin{array}{l}\text { Penjual kain } \\
\text { perca } \\
\text { Pemerintah desa }\end{array}$} & Sumber Daya Kunci & & Jalur & 2. Pengelola \\
\hline 2. & & $\begin{array}{ll}\text { 1. Kain Perca } \\
\text { 2. Alat cetak keset } \\
\text { kaki } \\
\text { 3. Gunting }\end{array}$ & & Penjual kain perca & $\begin{array}{l}\text { rumah sakit } \\
\text { 3. Pengelola } \\
\text { perkantoran } \\
\text { 4. Pengelola } \\
\text { losmen }\end{array}$ \\
\hline & \multicolumn{2}{|c|}{ Struktur Biaya } & & Pendapatan & \\
\hline
\end{tabular}


ABDIMAS: Jurnal Pengabdian Masyarakat Universitas Merdeka Malang

Volume 5, No 3, November 2020: 239-248

Pengrajin keset kaki sudah berhasil meningkatan kualitas soft skill terkait pemahaman konsep entrepreneurship. Pengrajin berhasil menyusun 9 blok pada Business Model Canvas (BMC).

\section{Sistem pengelolaan bisnis keset kaki yang berbasis entrepreneurship}

Bisnis keset kaki yang sebelumnya tidak memiliki segmen konsumen. Setelah mengikuti program PKM mulai menjalin kerjasama dengan komunitas pecinta barang daur ulang. Orang-orang pada komunitas ini membeli barang hasil daur ulang termasuk keset kaki yang berasal dari olahan limbah perca. Pengrajin keset kaki juga menjalin kerjasama dengan komunitas sosial disekitar lingkungan tempat tinggal. Pengrajin juga menjalin kerjasama dengan komunitas sosial yang diikuti pengrajin melalui ibu-ibu PKK dan komunitas pengajian Kecamatan Kademangan, komunitas sosial melalui kelompok sosial media di Facebook dan WhatsApp. Hasil dari pelatihan ini salah satunya dalam hal peningkatan ketrampilan dan penguasaan pemanfaatan jejaring sosial sebagai sarana alternatif untuk meningkatkan pemasaran dengan didukung oleh ketrampilan menghasilkan foto produk yang menarik (Susanti et al., 2019). Setiap pengrajin mulai menggunakan media sosial dan group keluarga sebagai media menjalin relasi dengan konsumen atau calon konsumen. Akses penerangan (listrik) dan internet belum maksimal. Desa Panggungduwet sering mati lampu sehingga masyarakat menggunakan genset mendapatkan listrik. Jaringan internet (sinyal) kurang stabil namun pengrajin tetap semangat untuk berinovasi pada block customer relationship. Pengrajin keset kaki secara rutin memeriksa jaringan listrik dan sinyal internet sehingga pengrajin tetap bisa melayani konsumen dan calon konsumen.

Inovasi pengelolaan bisnis berbasis entrepreneurship sudah eksekusi dimana, pengrajin juga merubah BMC. Inovasi dari Business Model Canvas (BMC) terletak pada aspek customer relationship. Pengrajin sudah membangun hubungan dengan konsumen dan calon konsumen dimana kegiatan ini sama sekali belum pernah dilakukan pengrajin sebelumnya. Visualisasi BMC yang sudah diinovasi pengrajin dapat dilihat pada Tabel 2.

Tabel 2. Inovasi BMC bisnis kerajinan keset kaki Desa Panggungduwet

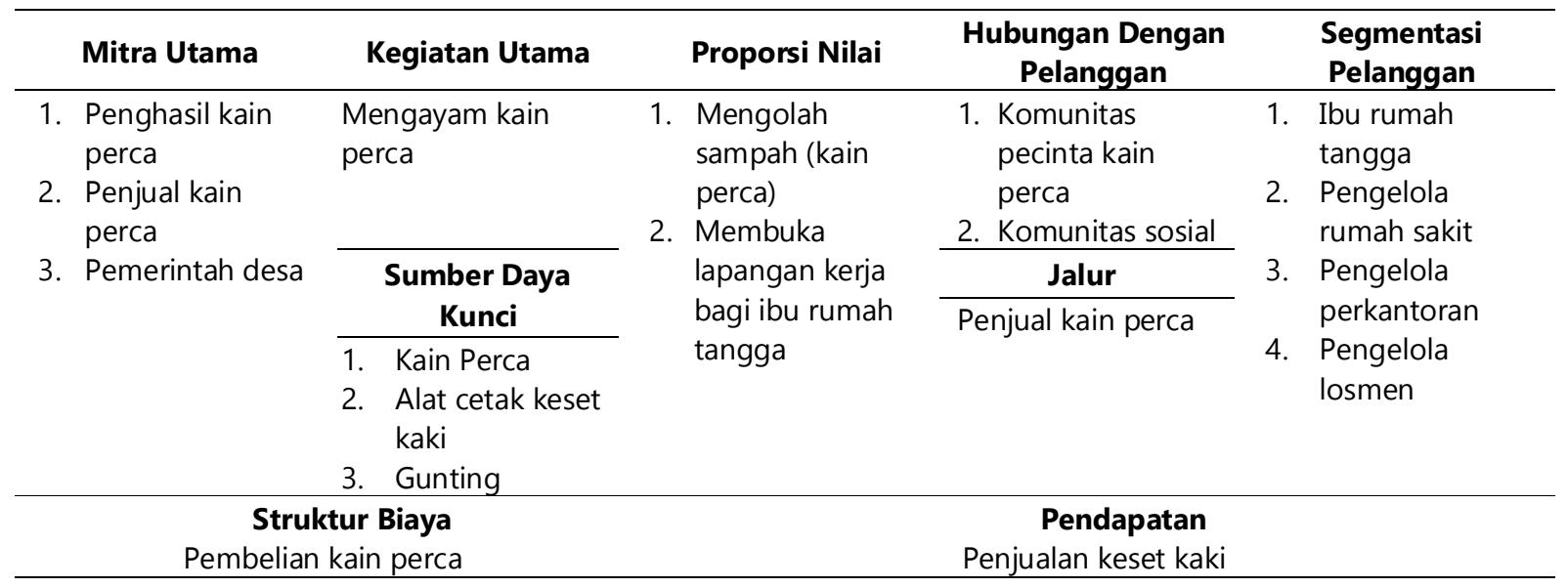

Inovasi bisnis yang dieksekusi pengrajin berhasil meingkatkan omset. Pengrajin menjual keset kaki tidak lagi terbatas kepada penjual kain perca melainkan merambah pada konsumen lain. Inovasi customer 
relationship meningkatkan kesadaran akan produk olahan limbah sehingga, pada akhirnya tertarik dan membeli produk keset kaki milik pengrajin Desa Panggungduwet.

\section{Membantu pemerintah menyelesaikan masalah pada sektor ekonomi Desa Panggungduwet}

Kegiatan PKM membantu pemerintah desa untuk menyelesaikan masalah ekonomi Desa Panggungduwet. Penduduk desa yang bukan berprofesi sebagai pengrajin melihat peningkatan pendapatan pengrajin keset kaki memutuskan bergabung menggeluti bisnis kerajinan keset kaki. Inovasi pengelolaan bisnis kerajinan keset kaki berhasil menyerap 30 orang tenaga kerja baru yang merupakan penduduk Desa Panggungduwet. Pengrajin keset kaki yang semula merintis bisnis mengalami perkembangan omset. Peningkatan omset pengrajin keset kaki meningkatkan profit bisnis yang pada akhirnya menambah pendapatan. Daya beli pengrajin juga meningkat. Perkembangan bisnis pengrajin keset kaki ini menjadi awal bagi pemerintah Desa Panggungduwet untuk mengembangkan bisnis di desa. Kehadiran pengrajin keset kaki yang berinovasi menyerap tenaga kerja sehingga pengangguran Desa Panggungduwet mengalami penurunan.

\section{SIMPULAN DAN SARAN}

\section{Simpulan}

PKM pengelolaan bisnis berbasis entrepreneurship pada pengrajin keset kaki Desa Panggungduwet memberikan multipler effect positif. Hasil dari kegiatan PKM bisa dirasakan oleh pengrajin, terukur pada kinerja bisnis keset kaki dan mengurangi jumlah orang miskin Desa Panggungduwet. Berikut ini hasil dari kegiatan PKM yang dirasakan oleh pengajin keset kaki dan dampak positif bagi perkembangan desa diantaranya: (1) Inovasi sistem pengelolaan bisnis keset kaki berbasis entrepreneurship dengan cara mengembangkan customer relationship (bergabung dengan komunitas pecinta barang daur ulang dan marketing melalui jalur komunitas sosial); (2) Inovasi media pemasaran menggunakan sosial media Facebook dan WhatsApp (sudah memanfaatkan teknologi) untuk menjual produk kerajinan yang dihasilkan; (3) Menciptakan lapangan kerja di Desa Panggungduwet dimana terdapat 20 orang ibu rumah tangga yang bergabung menjadi pengrajin keset kaki; (4) Pendapatan pengrajin keset kaki meningkat sebanyak 15\% karena adanya peningkatan jumlah konsumen; (5) Peningkatkan pemahaman pengrajin keset kaki pada konsep entrepreneurship (pengrajin keset kaki mampu mempelajari nilai (value), kapasitas (ability) dan sikap seseorang ketika menghadapi tantangan hidup untuk mendapat peluang dengan berbagai risiko yang mungkin dihadapinya selama menjalankan bisnis); (6) Peningkatan rasa percaya diri pengrajin dalam menjalankan operasional bisnis dan eksekusi penjualan produk dengan sistem online.

\section{Saran}

Pengrajin keset kaki Desa Panggungduwet sebaiknya menambah jumlah kerjasama dengan komunitas sosial lainnya untuk meningkatkan pemasaran produk keset kaki. Pengrajin keset kaki Desa Panggungduwet melanjutkan pembelajaran entrepreneurship dengan Universitas Ciputra Surabaya sehingga pengrajin mendapatkan pengetahuan dari sisi akademisi dan strategi bisnis. 
ABDIMAS: Jurnal Pengabdian Masyarakat Universitas Merdeka Malang

Volume 5, No 3, November 2020: 239-248

\section{DAFTAR PUSTAKA}

Dollinger, M. (2008). Entrepreneurship. Marsh Publications.

Hadiyati, E. (2011). Kreativitas dan inovasi berpengaruh terhadap kewirausahaan usaha kecil. Jurnal Manajemen dan Kewirausahaan, 13(1), 8-16. https://doi.org/10.9744/jmk.13.1.8-16

Harahap, K., \& Amanah, D. (2018). Peningkatan daya saing usaha mukena dan keset kaki di Kecamatan Percut Sei Tuan. Jurnal Pengabdian Kepada Masyarakat, 24(1), 502-509. https://doi.org/10.24114/ jpkm.v24i1.8940

Harini, S. (2014). Pengaruh Pelatihan Entrepreneurship dan manajemen usaha terhadap pendapatan Usaha Mikro makanan dan minuman. Jurnal Entrepreneur dan Entrepreneurship, 3(1, 2), 73-80.

Hisrich, R. D., Peters, M. P., \& Shepherd, D. A. (2005). Entrepreneurship. 6th Edition. Boston: Mc Graw Hill.

Lestari, I., Astuti, M., \& Ridwan, H. (2019). Pengaruh inovasi dan orientasi kewirausahaan terhadap keunggulan bersaing UMKM kuliner. Jurnal Riset Manajemen dan Bisnis (JRMB) Fakultas Ekonomi UNIAT, 4(1), 111-118. https://doi.org/10.36226/jrmb.v4i1.245

Mangowal, J. (2013). Pemberdayaan masyarakat petani dalam meningkatkan pengembangan ekonomi pedesaan di Desa Tumani Kecamatan Maesaan Kabupaten Minahasa Selatan. Governance, 5(1).

Osterwalder, A., \& Pigneur, Y. (2010). Business model generation: A handbook for visionaries, game changers, and challengers. John Wiley Sons.

Subroto, W. T. (2015). Menanamkan nilai-nilai entrepreneurship melalui pendidikan ekonomi pada era masyarakat ekonomi Asean. Jurnal Economia, 11(1), 16-25. https://doi.org/10.21831/economia.v11i1.7751

Suryana, A., Zein, D., Sumartias, S., \& Gemiharto, I. (2019). Pengaruh strategi komunikasi pemasaran, budaya organisasi, karakteristik individu inovatif dan komitmen organisasional terhadap kinerja usaha kecil dan menengah. Jurnal Manajemen Komunikasi, 3(2), 185-201. https://doi.org/10.24198/jmk.v3i2.20754

Susanti, N., Irawan, Y., \& Triyanto, W. A. (2019). Pendampingan E-Commerce bagi pengrajin tas. Muria Jurnal Layanan Masyarakat, 1(2), 47-50. https://doi.org/10.24176/mjlm.v1i2.3756

Susita, D., Mardiyati, U., \& Aminah, H. (2017). Pelatihan kewirausahaan bagi pelaku usaha kecil dan binaan koperasi di rumah susun sederhana sewa (rusunawa) Cipinang Besar Selatan. Jurnal Pemberdayaan Masyarakat Madani (JPMM), 1(1), 58-72. https://doi.org/10.21009/JPMM.001.1.05 